\title{
ENHANCED GAIN AND BANDWIDTH OF PATCH ANTENNA USING EBG SUBSTRATES
}

\author{
Mst. Nargis Aktar ${ }^{1}$, Muhammad Shahin Uddin ${ }^{2}$, Md. Ruhul Amin ${ }^{3}$, and \\ Md. Mortuza Ali ${ }^{4}$ \\ ${ }^{1}$ Department of Information and Communication Technology \\ Mawlana Bhashani Science and Technology University, Bangladesh \\ ${ }^{2}$ Department of Electronics, Kookmin University, Seoul, South Korea \\ ${ }^{3}$ Department of Electrical and Electronic Engineering \\ Islamic University of Technology, Dhaka, Bangladesh \\ ${ }^{4}$ Department of Electrical and Electronic Engineering \\ Rajshahi University of Engineering and Technology, Bangladesh \\ E-mail: \{nargismbstulgmail.com, shahin.mbstulgmail.com, \\ aminr_bd@yahoo.com, and mmali.ruet@gmail.com\}
}

\begin{abstract}
Microstrip patch antenna becomes very popular day by day because of its ease of analysis and fabrication, low cost, light weight, easy to feed and their attractive radiation characteristics. Although patch antenna has numerous advantages, it has also some drawbacks such as restricted bandwidth, low gain and a potential decrease in radiation pattern. In recent years, attention to use Electromagnetic Band Gap (EBG) substrates to overcome the limitations of patch antenna. In this paper, we propose a rectangular microstrip patch antenna with EBG substrates and compare the performance of the proposed antenna with a conventional patch antenna in the same physical dimension. Due to the presence of the $E B G$ structure in the dielectric substrates, the electromagnetic band gap is created that reduces the surface waves considerably. As a result, the performance of the proposed antenna is better comparing the conventional existing microstrip patch antenna.
\end{abstract}

\section{KEYWORDS}

Microstrip patch antenna, Electromagnetic band gap (EBG) substrates, Gain and Bandwidth.

\section{INTRODUCTION}

With the drastic demand of wireless communication system and their miniaturization, antenna design becomes more challenging. Recently microstrip patch antennas have been widely used in satellite communications, aerospace, radars, biomedical applications and reflector feeds because of its inherent characteristics such as light weight, low profile, low cost, mechanically robust, compatibility with integrated circuits and very versatile in terms of resonant frequency, polarization, pattern and impedance. In spite of its several advantages, they suffer from drawbacks such as narrow bandwidth, low gain and excitation of surface waves, etc [1-3]. These drawbacks limit their applications in other fields. In order to overcome the limitations of microstrip patch antennas such as narrow bandwidth and low gain, numerous techniques are proposed i.e. for probe fed stacked antenna, microstrip patch antennas on electrically thick substrate, slotted patch antenna and stacked shorted patches have been proposed and investigated [4-5]. These methods have eliminated the bandwidth problem for most applications. But limitations of gain and surface wave excitation still remain. That is why, in recent years there has been considerable effort in the EBG structure for antenna application to suppress the surface wave and overcome the limitations of the antenna. Many works have been done to 
improve the performance of the microstrip antennas [6-11]. The EBG structure utilizes the inherent properties of dielectric materials to enhance the microstrip antenna performance. EBG materials are periodic dielectrics that produce pass band and stop band characteristics.

In this paper, we propose a rectangular patch antenna with EBG substrates. The characteristics of EBG depend on the shape, size, symmetry and the material used in their construction. Surface waves are reduced by using EBG substrate which leads to increase the directivity, bandwidth and radiation efficiency [15]. EBG were realized to reduce and eliminate surface waves, which leads to an increase in directivity, bandwidth and radiation efficiency. It is also useful to reduce the side lobes of the radiation pattern and hence radiation pattern front-toback ratio and overall antenna efficiency are improved. Our proposed antenna gives better performance compare to the conventional rectangular microstrip patch antenna. A substantial gain and bandwidth enhancement has been obtained. The design and simulation have been done by using High Frequency Structure Simulator (HFSS). The remainder of the paper is organized as follows: In section II, a brief description of EBG structure. In section III present the conventional and proposed antenna design and configuration. In section IV present the simulation results and discussion. The conclusion of this paper is provided in section V.

\section{EleCtromagnetic BAND GAP SUbSTRATES}

The birth of the electromagnetic band gap structure has triggered many novel antenna applications. Electromagnetic band gap structures can be defined as artificial periodic (or sometimes non-periodic) objects that prevent or assist the propagation of electromagnetic waves in a specified band of frequency for all incident angle and polarization state. Two commonly employed features are suppressing unwanted substrate modes and acting as an artificial magnetic ground plane. The main advantage of EBG structure is their ability to suppress the surface wave current. The generation of surface waves degrades the antenna efficiency and radiation pattern. Furthermore, it increases the mutual coupling of the antenna array which causes the blind angle of a scanning array [12-14].

EBG structures are usually realized by periodic arrangement of dielectric materials and metallic conductors. In general, they can be categorized into three groups according to their geometric configuration; (i) three-dimensional volumetric structures, (ii) two-dimensional planar surfaces, and (iii) one-dimensional transmission lines [13]. Two-dimensional planar EBG surfaces again classified into two categories, first one is mushroom like EBG surfaces and another one is uniplanar EBG surfaces.

For the mushroom like EBG surfaces, a band gap is observed between the frequency $7 \mathrm{GHz}$ and $11 \mathrm{GHz}$. On the other hand, for the uniplanar EBG surfaces a band gap is observed the frequency from $13 \mathrm{GHz}$ to $14.6 \mathrm{GHz}$. In this paper, mushroom like EBG surface is used in order to design patch antenna on EBG substrates because the mushroom like EBG surface has a lower frequency band gap and a wider bandwidth than the uniplanar EBG surface.

A two dimensional mushroom like EBG structure is shown in Figure 1. Design of patch antenna mushroom like EBG structures are preferable because light weight, low fabrication cost. There are four main parameters affecting the performance of mushroom like EBG structures. The parameters are like this: rectangle width $w$, gap width g, substrates thickness $h$ and substrates permittivity $\varepsilon_{r}$. Also, the vertical vias radius $r$ has a trival effect because it is very thin compared to the operating wavelength. The parameters that are affecting the performance of EBG structures are directly dependent on the operating wavelength of the patch antenna [8]. The parameters are varying with operating wavelength as like this that the rectangle width, $w$ varies from $0.04 \lambda_{12 \mathrm{GHz}}$ to $0.20 \lambda_{12 \mathrm{GHz}}$, gap width varies from $0.01 \lambda_{12 \mathrm{GHz}}$ to $0.12 \lambda_{12 \mathrm{GHz}}$ and the substrate thickness, $h$ varies from $0.01 \lambda_{12 \mathrm{GHz}}$ to $0.09 \lambda_{12 \mathrm{GHz}}$. Here, $\lambda_{12}$ means the wavelength between medium 1 and 2 i.e. the free space and the guiding device and $\mathrm{GHz}$ means the wavelength respect to the $\mathrm{GHz}$ range frequency. 

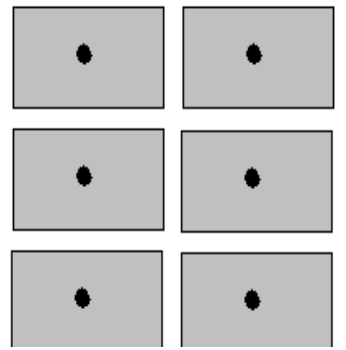

(a) Top view

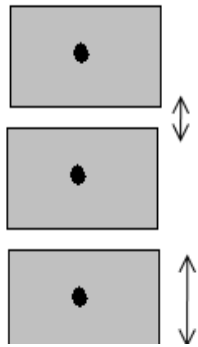

Gap Width

Rectangle

Width (b) Cross view

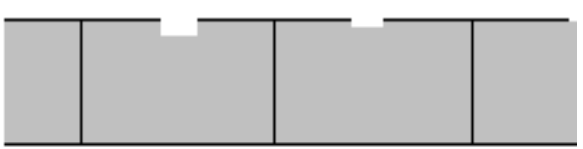

Figure 1 Two dimensional mushrooms like EBG surfaces: (a) Top view (b) Cross view

\section{ANTENNA DESIGN AND CONFIgURATION}

In order to identify and verify the improvement of the performance of microstrip antenna on EBG substrates, designed a conventional antenna and the proposed antenna. The width of the rectangular patch antenna is usually chosen to be larger than the length of the patch, L to get higher bandwidth. The antenna is designed to operate at frequency $10 \mathrm{GHz}$. In this paper, we use neltec dielectric material as patch substrates whose dielectric constant is 2.45 . The antenna is excited by a microstrip transmission line feed. The point of excitation is adjustable to control the impedance match between feed and antenna, polarization, mode of operation and excitation frequency. To design patch antenna lower dielectric constant is used because in case of lower dielectric constant of the substrates, surface wave losses are more severe and dielectric and conductor losses are less severe. By using EBG structures, surface wave loss can be reduced easily. Table1 shows the important parameters for the geometrical configuration of the patch antenna.

Table1 Geometrical configuration of the patch antenna

\begin{tabular}{|l|l|l|}
\hline Antenna Part & Parameter & Value \\
\hline \multirow{3}{*}{ Patch } & Length & $8.8 \mathrm{~mm}$ \\
\cline { 2 - 3 } & Width & $11.4 \mathrm{~mm}$ \\
\hline \multirow{2}{*}{$\begin{array}{l}\text { Patch Substrates } \\
\text { (NeltecNx9245) } \\
(\mathrm{IM})(\mathrm{tm})\end{array}$} & Dielectric constant & 2.45 \\
\cline { 2 - 3 } & Height & $0.787 \mathrm{~mm}$ \\
\cline { 2 - 3 } & Dielectric loss tangent & 0.01 \\
\hline \multirow{3}{*}{ EBG Substrates } & Rectangle Width & $0.10 \lambda_{12 \mathrm{GHz}}$ \\
\cline { 2 - 3 } & Gap Width & $0.02 \lambda_{12 \mathrm{GHz}}$ \\
\cline { 2 - 3 } & Substrates thickness & $0.04 \lambda_{12 \mathrm{GHz}}$ \\
\hline Operating Frequency & & $10 \mathrm{GHz}$ \\
\hline
\end{tabular}




\section{SIMULATION RESULTS AND DISCUSSIONS}

Now a days, it is a common practice to evaluate the system performances through computer simulation before the real time implementation. A simulator "Ansoft HFSS" based on finiteelement method (FEM) has been used to calculate return loss, impedance bandwidth, radiation pattern and gains. This simulator also helps to reduce the fabrication cost because only the antenna with the best performance would be fabricated. Figure 2 shows the simulated results of the return loss of the conventional antenna and the proposed antenna.

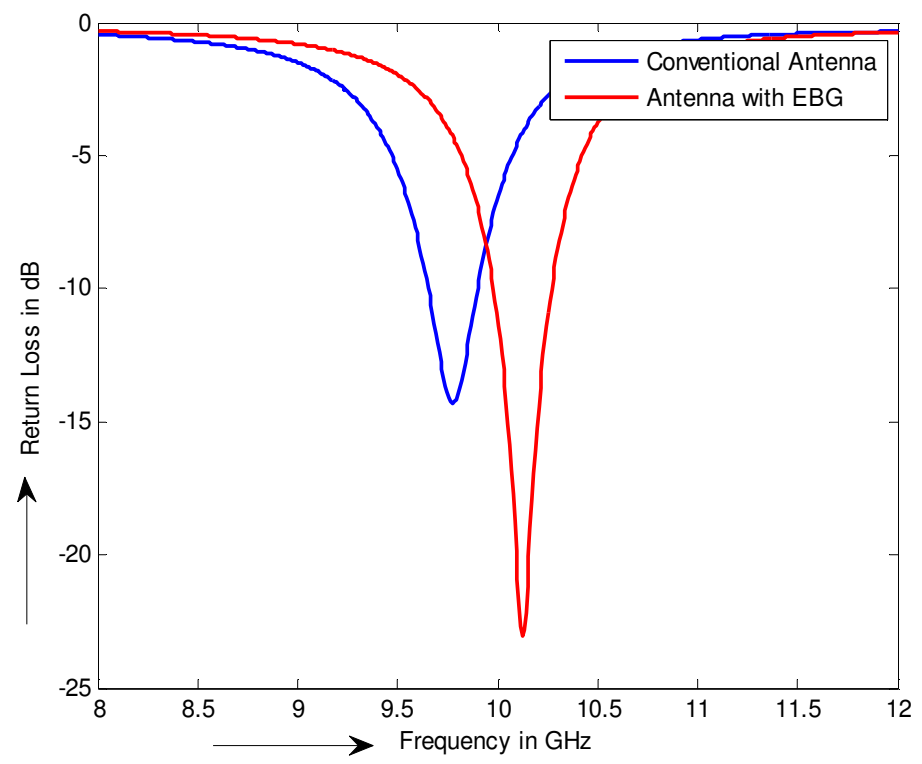

Figure 2 Return losses of the conventional patch antenna and antenna with EBG

It is seen from the Figure 2, the return loss for the conventional patch antenna is $-14.5 \mathrm{~dB}$ at $9.79 \mathrm{GHz}$ and for the proposed patch antenna is $-23 \mathrm{~dB}$ at $10.12 \mathrm{GHz}$. A negative value for return loss shows that this antenna had not many losses while transmitting the signals. According to theoretical design, the minimum loss has been observed at $10 \mathrm{GHz}$. But from simulation results we have observed that the minimum loss get at $9.79 \mathrm{GHz}$ for conventional antenna and $10.12 \mathrm{GHz}$ for the proposed antenna. Thus the return loss of the proposed microstrip patch antenna is $58.6 \%$ less compared to the conventional microstrip patch antenna. From the same Figure 2, the antenna bandwidth can be calculated. At the point of return loss $-10 \mathrm{~dB}$, the bandwidth $(\mathrm{BW})$ and the relative bandwidth $(\mathrm{RBW})$ are $240 \mathrm{MHz}$ and $5.43 \%$ for conventional patch antenna but at same point of return loss the bandwidth (BW) and the relative bandwidth (RBW) of the proposed antenna are $330 \mathrm{MHz}$ and $7.33 \%$. Therefore, the bandwidth of the proposed antenna is $37.5 \%$ more than the conventional antenna.

The simulated results for gain that are obtained from conventional antenna and the proposed antenna on EBG substrates are shown in Figure 3 and Figure 4. 
International Journal of Wireless \& Mobile Networks (IJWMN) Vol. 3, No. 1, February 2011

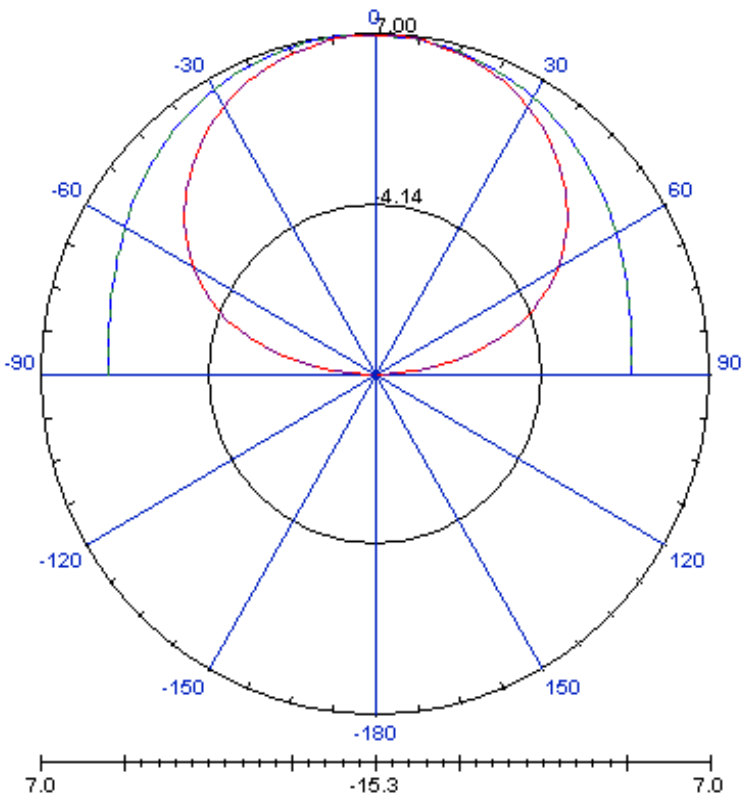

Figure 3 Gain of the conventional rectangular patch antenna.

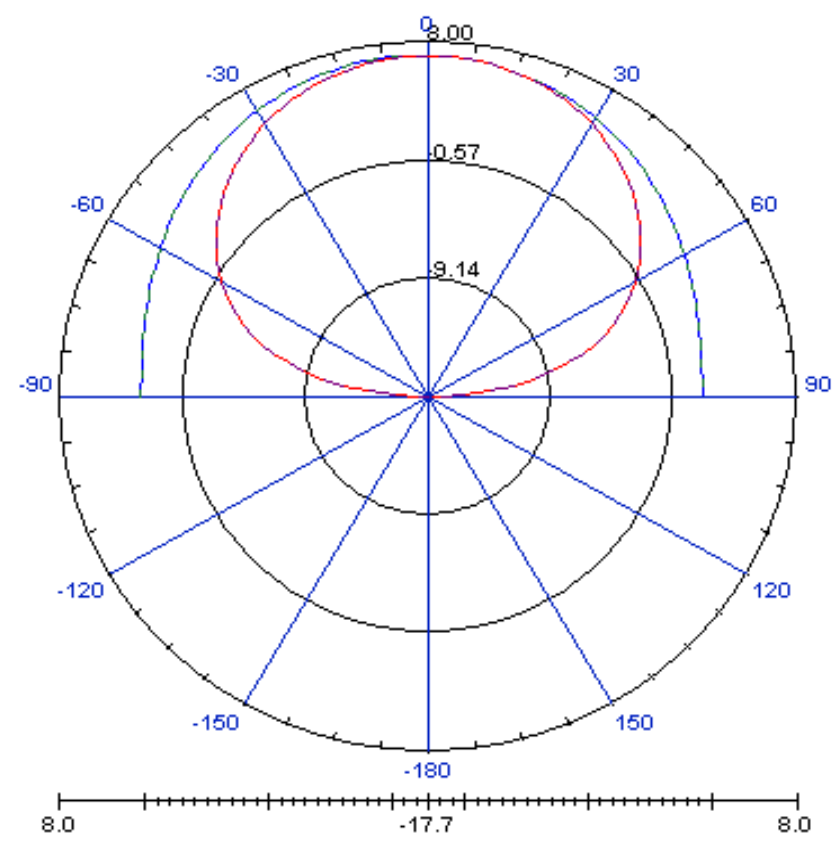

Figure 4 Gain of the rectangular patch antenna with EBG

From the simulated results, it is shown that the gain of the conventional antenna and the proposed antenna is $22.3 \mathrm{~dB}$ and $25.7 \mathrm{~dB}$. So, the gain of the proposed patch antenna on EBG substrates is $15.2 \%$ more than the conventional patch antenna. 
The Figure 5 and Figure 6 shows the simulated directivity of the conventional antenna and the proposed antenna.

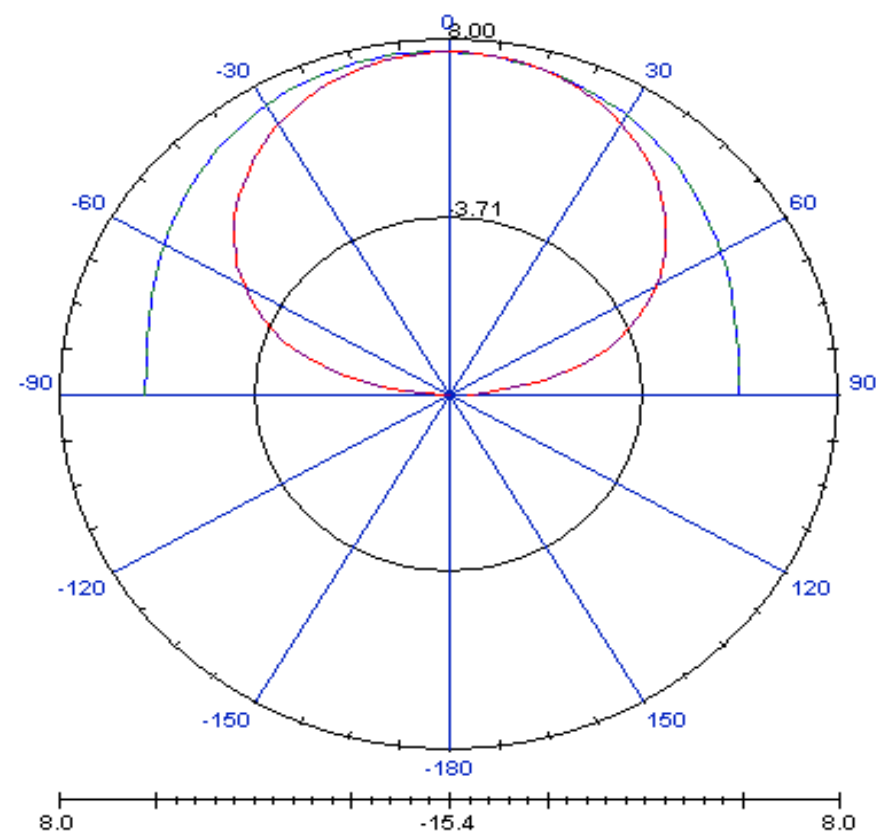

Figure 5 Directivity of the conventional rectangular patch antenna.

From the Figure 5 and Figure 6, the directivity for the conventional patch antenna and the proposed patch antenna are $23.4 \mathrm{dBi}$ and $25.5 \mathrm{dBi}$. Thus, the directivity of the proposed antenna is also enhanced of $8.97 \%$ than the conventional antenna.

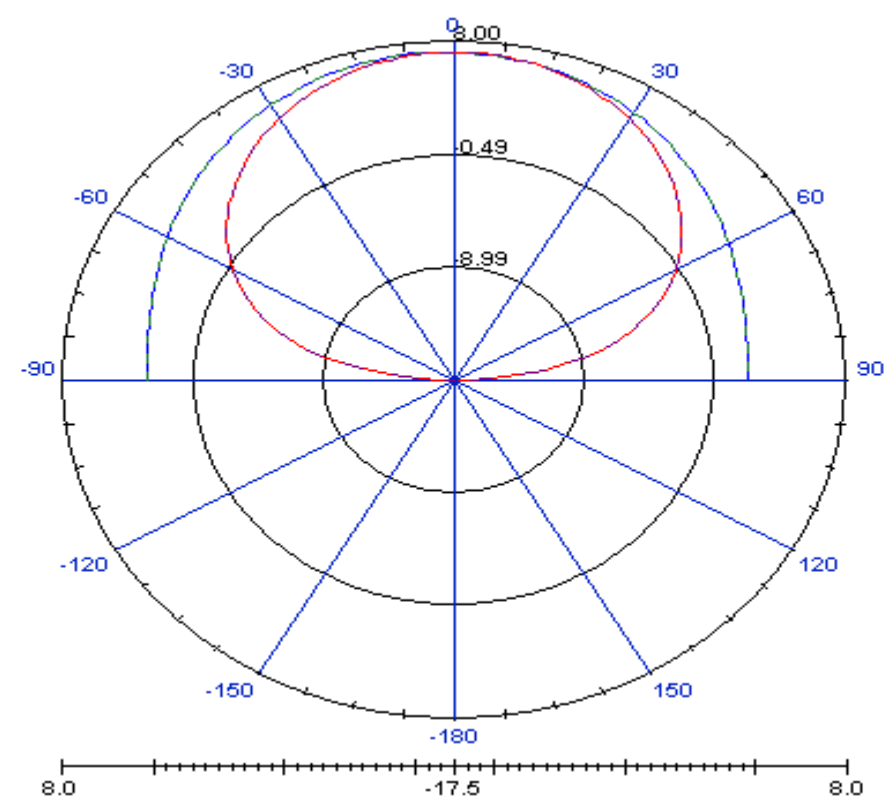

Figure 6 Directivity of the rectangular patch antenna with EBG 
International Journal of Wireless \& Mobile Networks (IJWMN) Vol. 3, No. 1, February 2011

\section{CONCLUSION}

The patch antenna mostly used in modern mobile communication. The goals of this paper are to design conventional patch antenna and the patch antenna on EBG substrates with same physical dimensions that can operate at $10 \mathrm{GHz}$ and study the performance of misrostrip antenna when EBG structure added on it. From the simulated results, it is seen that the performance is better of a patch antenna that is designed on EBG substrates than the conventional patch antenna. In future, our targets are to real time implementation of the proposed antenna and also design another microstrip patch antenna with EBG substrates that can operate at higher frequency.

\section{References}

[1] Jing Liang, and Hung-Yu David Yang, "Radiation Characteristics of a Microstrip Patch over an Electromagnetic Bandgap Surface," IEEE Transactions on Antennas and Propagation, Vol. 55, June 2007, pp1691-1697.

[2] Mohammad Tariqul Islam, Mohammed Nazmus Shakib, Norbahiah Misran, and Baharudin Yatim, "Analysis of Broadband Slotted Microstrip Patch Antenna," Proceedings of the International Conference on Computer and Information Technology, December 2008, pp. 758-761.

[3] K.L. Wong, Compact and Broadband Microstrip Antennas. New York: Wiley, 2002.

[4] D. N. Elsheakh, IEEE, H. A. Elsadek, E. A. Abdallah, H. Elhenawy, and M. F. Iskander, "Enhancement of Microstrip Monopole Antenna Bandwidth by Using EBG Structures," IEEE Antennas and Wireless Propagation Letters, vol. 8, 2009, pp 959-962.

[5] S. Pioch and J.M. Laheurte, "Low Profile Dual-Band Antenna Based on a Stacked Configuration of EBG and Plain Patches," Microwave. Opt. Tech. Letter, vol. 44, February 2005, pp. 207-209.

[6] D. Qu, L. Shafai and A. Foroozesh, "Improving Microstrip Patch Antenna Performance Using EBG Substrates,” IEE Proc. Micro. Antennas Propagation, Vol.153, December 2006, pp.558-563.

[7] G. S. Kliros, K. S. Liantzas, A. A. Konstantinidis, "Modeling of Microstrip Patch Antennas with Electromagnetic Band Gap Superstrates," 19th International Conference on Applied Electromagnetics and Communications, 2007.

[8] Ram'on Gonzalo, Peter de Maagt, and Mario Sorolla, "Enhanced Patch-Antenna Performance by Suppressing Surface Waves Using Photonic-Bandgap Substrates," IEEE Transactions on Microwave Theory and Techniques, Vol. 47, November 1999, pp. 2131-2138.

[9] Atsuya Ando, Kenichi Kagoshima, Akira Kondo, and Shuji Kubota, "Novel Microstrip Antenna With Rotatable Patch Fed by Coaxial Line for Personal Handy-Phone System Units," IEEE Transactions on Antennas and Propagation, Vol. 56, August 2008, pp.2747-2751.

[10] Mr. Pramod Kumar.M , Sravan kumar, Rajeev Jyoti , VSK Reddy, PNS Rao,"Novel Structural Design for Compact and Broadband Patch Antenna," IEEE 2010.

[11] R. Chantalat, C. Menudier, M. Thevenot, T. Monediere, E. Arnaud, and P. Dumon,"Enhanced EBG Resonator Antenna as Feed of a Reflector Antenna in the Ka Band," IEEE Antennas and Wireless Propagation Letters, Vol. 7, 2008 pp.349-353

[12] Nasimuddin, Zhi Ning Chen, Terence S. P. See, and Xianming Qing, "Multi-dielectric Layer MultiPatches Microstrip Antenna for UWB Applications," Proceedings of the 37th European Microwave Conference, Munich Germany, October 2007, pp 1019-1021

[13] Fan Yang, Yahya Rahmat Sami, "Electromagnetic band Gap Structures in Antenna Engineering," Cambridge University Press 2009.

[14] Constantine A. Balanis, “Antenna Theory Analysis and Design," Third Edition, John Wiley \& Sons, 2005

[15] D. M. Pozar, "Microwave Engineering," Third edition. New York, Wiley, 2005. 
Authors

Mst. Nargis Aktar received B.Sc. and M.Sc. in Electrical and Electronic Engineering from Rajshahi University of Engineering and Technology (RUET), Bangladesh in 2007 and 2010 respectively. She joined as a faculty member in Electrical and Electronic Engineering department of Ahsanullah University of Science \& Technology (AUST), Bangladesh, in 2007. In 2008 she joined as a faculty member in the department of Information and Communication Technology (ICT) of Mawlana Bhashani Science and

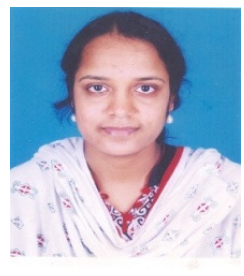
Technology University (MBSTU), Bangladesh. Her current research interests focus on Antenna designing, optical communication, photonics.

Muhammad Shahin Uddin received B.Sc. in Electrical and Electronic Engineering from Rajshahi University of Engineering and Technology (RUET), Bangladesh. Then, he joined as a faculty member in American International University Bangladesh (AIUB) and Chittagong University of Engineering and Technology (CUET), Bangladesh in 2005. In 2006 he joined as a faculty member in the department of ICT of Mawlana Bhashani Science and Technology University (MBSTU), Bangladesh. Currently he is continuing his Masters studies in the department of Electronics Engineering of Kookmin University, Korea. His current research interests are Visible Light Communication, RFID, LED-ID, Sensor Network Smart Antenna Design and Wireless Cellular Networks.

Dr. Md. Ruhul Amin is working as a Professor in Electrical and Electronic Engineering at the Islamic University of Technology, a subsidiary organ of OIC. He earned a Ph. D. in EEE from Niigata University, Japan, M. Sc. Engineering from Bangladesh University of Engineering and Technology and B. Sc Engineering from the University of Rajshahi. His research interests include generation and application of High Power Microwaves, Antenna theory and Signal Processing. He was the recipient of the Sir Thomas Ward memorial medal awarded by the Institution of Engineers India. Professor

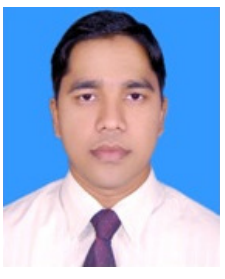
Amin has published 66 journal and conference papers so far. He served as the Dean of the Faculty of Electrical and Computer Engineering at Rajshahi University of Engineering and Technology. Professor Amin is a Commonwealth Fellow and a Fellow of the Institution of Engineers, Bangladesh and a member of IEEE.

Dr. Md. Mortuza Ali was born in Bangladesh in 1957. He received the B. Sc. Engineering degree in Electrical and Electronic Engineering from Rajshahi University, Bangladesh in 1982, and the M. Sc. and Ph. D. degrees from Niigata University, Japan in 1989 and 1992, respectively. Since 2002 he has been employed by Rajshahi University of Engineering \& Technology, Bangladesh as Professor in the Department of Electrical and Electronic Engineering. His research interests include the high power microwave devices, antennas and wave propagation, and numerical analyses of various

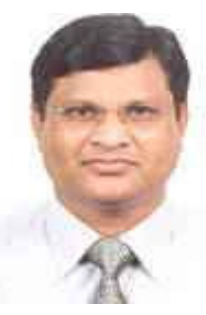
systems of linear/nonlinear equations. 